\title{
THERMOGENIC CAPABILITIES OF THE OPOSSUM MONODELPHIS DOMESTICA WHEN WARM AND COLD ACCLIMATED: SIMILARITIES BETWEEN AMERICAN AND AUSTRALIAN MARSUPIALS
}

\author{
T. J. DAwson* and J. M. OLSON \\ Museum of Zoology, University of Michigan, Ann Arbor, MI 48109, USA
}

(Received 24 April 1987)

\begin{abstract}
Monodelphis domestica is a small marsupial mammal from South America. Its thermogenic abilities in the cold were determined when the opossums were both warm (WA) and cold (CA) acclimated. Maximum heat production of $M$. domestica was obtained at low temperatures in helium-oxygen.

2. Basal metabolic rate (BMR) in the WA animals was $3.2 \mathrm{~W} / \mathrm{kg}$ and mean body temperature was $32.6^{\circ} \mathrm{C}$ at $30^{\circ} \mathrm{C}$. These values were lower than those generally reported for marsupials. Nevertheless, these $\boldsymbol{M}$. domestica showed considerable metabolic expansibility in response to cold. Sustained (summit) metabolism was 8-9 times BMR, while peak metabolism was $11-13$ times BMR. These maximum values were equal to, or above, those expected in small placentals.

3. Cold acclimation altered the thermal responses of $M$. domestica, particularly in warm $T_{\mathrm{a}} \mathrm{s}$. However, summit metabolism was not significantly increased; nor did $M$. domestica show a significant thermogenic response to noradrenaline, which in many small placentals elicits non-shivering thermogenesis.

The thermoregulatory responses of this American marsupial were, in most aspects, similar to those of Australian marsupials. This suggests that the considerable thermoregulatory abilities of marsupials are of some antiquity.
\end{abstract}

\section{INTRODUCTION}

Differences in the metabolic relationships of marsupial and placental mammals are now generally accepted, at least at the level of basal or standard metabolism (Dawson and Hulbert, 1969, 1970; MacMillen and Nelson, 1969; McNab, 1978; Hinds and MacMillen, 1984). The impact of the relatively low basal metabolic rate (BMR) of the marsupials on their temperature regulation and metabolic capabilities is, however, still unclear. Dawson (1973) suggested that a lower rate of heat loss could compensate marsupials for a reduced metabolic potential in response to cold (relative to that seen in the placentals). However, Dawson and Dawson (1982) and Hinds and MacMillen (1984) have indicated that such a reduced heat loss was not apparent in small marsupials. Set against these suggestions are recent findings that, in response to cold, some small Australian marsupials have a greater proportional metabolic scope than do placentals (Dawson and Dawson, 1982; Smith and Dawson, 1985).

Much of the discussion about the differences in BMR between marsupials and placentals centres on whether these reflect adaptation to various environmental factors (McNab, 1978) or conservative phylogenetic states. Many mammals with conservative features, placentals included, show relatively low levels of basal metabolism and body temperature (Dawson, 1973). Marsupials from Australia and America have had a long evolutionary separation,

*Permanent address for correspondence: School of Zoology, University of New South Wales, PO Box 1, Kensington, NSW 2033, Australia. Telephone: 697-2222. with the Australian forms being considered to represent a more recent radiation (Archer, 1984). The separation of these two groups occurred as long ago as the early Tertiary, some 50-60 million years ago. Consequently, comparison of the thermoregulatory characteristics of these two groups may be pertinent to this debate.

Australian marsupials are very competent homeotherms (Dawson, Robertshaw and Taylor, 1974; Dawson and Dawson, 1982; Dawson, 1983). The question then arises as to whether the Australian lines have built upon a set of conservative features or do all marsupials share characteristic metabolic capabilities? To provide insight into this question we have examined the thermoregulatory capacities of the didelphid opossum Monodelphis domestica.

We have also studied the heat balance in warm and cold acclimated animals because the metabolic capacities of small mammals may change markedly when they are acclimated to different environmental temperatures. Such changes in placentals are associated with non-shivering thermogenesis (NST) (Jansky, 1973), which may involve the thermogenic tissue, brown adipose tissue (BAT) (Cannon and Nedergaard, 1983; Nicholls and Locke, 1984). There is doubt as to the occurrence of BAT in marsupials (Rowlatt et al., 1971; Rothwell and Stock, 1985) and the response to cold acclimation may differ between marsupials and placentals (Smith and Dawson, 1985).

\section{MATERIALS AND METHODS}

\section{Animals}

The $M$. domestica were purchased as non-breeding stock from the Southwest Foundation for Biomedical Research, 
PO Box 28147, San Antonio, TX 78284, USA, the original stock having come from the Caatinga region of southeastern Brazil. Details for the care and maintenance of the animals are given by Fadem et al. (1982). Our animals (four male and four female) were housed individually and fed a diet of dry pellets (fox reproductive diet, Milk Speciality Products, New Hollstein, Wisconsin), canned dog food and crickets. Mass was maintained on this diet during warm acclimation near $115 \mathrm{~g}$ for males and $83 \mathrm{~g}$ for females. During cold acclimation there was an initial loss of $5-10 \%$ in some animals but mass was maintained thereafter.

During acclimation to the warm and cold environments the animals were maintained in constant temperature rooms on a 12:12 day-night cycle. The warm acclimated (WA) animals were kept at $25-27^{\circ} \mathrm{C}$. The same group of animals were subsequently cold acclimated (CA) by being kept at $10-12^{\circ} \mathrm{C}$ for at least 3 weeks before examination. Some opossums died when maintained at a $T_{\mathrm{a}}$ of $5^{\circ} \mathrm{C}$. Smith and Dawson (1984) showed that acclimation was completed within this period in the marsupial, Dasyuroides byrnei.

\section{Experimental procedures}

Heat production in both WA and CA animals was estimated from oxygen consumption at ambient temperatures $\left(T_{\mathrm{a}}\right)$ between 5 and $30^{\circ} \mathrm{C}$ in air and at 10 and $15^{\circ} \mathrm{C}$ in a helium-oxygen atmosphere (helox). The thermal conductance of helium is approx. 6 times that of nitrogen, A gas mixture in which helium replaces nitrogen can therefore be used to elicit maximum responses to cold stress, while limiting the possibility of cold injury to tissue (Rosenmann and Morrison, 1974; Smith and Dawson, 1985). As well as increasing heat loss from an animal, there is some evidence that helium can affect lung ventilation volume but this would seem to be a relatively minor effect in this context (Brice and Welsh, 1983).

Experiments were carried out in a temperature controlled cabinet regulated to $\pm 1^{\circ} \mathrm{C}$. The cabinet was lighted and experiments were generally carried out during the light phase of the photocycle. Fresh food was withheld for at least 3-4 hr prior to experiments. Unrestrained animals were placed in an airtight metabolic chamber of 3.81 effective capacity. The chamber was made of thin metal, which was internally coated black to minimize reflected thermal radiation (Porter, 1969). It had a Plexiglass window so that the animals could be regularly observed. The appropriate gas mixtures were metered through the chamber at constant rates, either 0.5 or $1.0 \mathrm{l} / \mathrm{min}$, by a Brooks thermal mass flow meter (Model 5841-AIAZMN). The flow meter had been calibrated for both air and helox.

Once the animal had been placed within the metabolic chamber, oxygen consumption was determined using an Applied Electrochemistry analyser (Model S-3A). The electrical outputs of the analyser and the flow controller, together with the output from the chamber thermocouple, were fed into an Apple 1le computer. This enabled oxygen consumption to be calculated on an "instantaneous" basis using the method of Bartholomew, Vleck and Vleck (1981), with the values being printed out each minute. This procedure enables the determination of the time course of actual metabolic responses and additionally, it allows the accurate monitoring of the animal's status. Consequently, an animal could be safely removed from the chamber if its metabolic abilities appeared to be overtaxed, as may occur in helox. Oxygen consumption was converted to heat production (HP) in units of $W / \mathrm{kg}$ by assuming a respiratory quotient $(\mathrm{RQ})$ of $0.8\left(11 \mathrm{O}_{2} / \mathrm{kg}\right.$ per hr $\left.=5.59 \mathrm{~W} / \mathrm{kg}\right)$. At the coldest temperatures the $R Q$ was probably closer to 0.7 , due to a greater metabolism of fat (Dawson and Dawson, 1982), but the potential error in calculated HP is small.

Heat production at a specific air temperature was determined after the animal had been allowed to equilibrate to the temperature for approx. $3 \mathrm{hr}$ and was then measured as the mean of two 15 min periods when the animal was resting. For exposures in helox we accepted a shorter initial equilibration time, $2 \mathrm{hr}$, because the effective reduction in the insulation of the fur meant that the opossums reached thermal equilibrium very quickly. Summit metabolism was determined as the maximum heat production that was achieved in these conditions, i.e. that sustained for longer than 2 hr (Dawson and Dawson, 1982). Peak metabolic rates, i.e. those reached for a few minutes, were assessed as the maximum rates seen over a 5-8 min period during the exposure in helox at $10^{\circ} \mathrm{C}$. Such levels were seen within the first $20 \mathrm{~min}$ of the exposure.

Body temperature $\left(T_{\mathrm{b}}\right)$ was measured as deep colonic temperature, insertion depth $3-4 \mathrm{~cm}$, using calibrated copper-constantan thermocouples. Body temperatures were taken immediately before and after each experimental run.

The thermal conductance was calculated by the equation:

$$
C\left(\mathrm{~W} / \mathrm{m}^{2} \text { per }{ }^{\circ} \mathrm{C}\right)=H P /\left(T_{\mathrm{b}}-T_{\mathrm{a}}\right) S A
$$

where $S A=$ surface area in $\mathrm{m}^{2}$, calculated by the equation $S A=0.1 \mathrm{~W}^{0.67}(\mathrm{~kg})$ (Dawson and Dawson, 1982). This calculation of conductance neglects heat loss by evaporative cooling. At the generally low ambient temperatures used in these experiments, heat loss by evaporation would be of minor importance.

In placentals non-shivering thermogenesis may be mediated by noradrenaline. The effect of noradrenaline on the thermogenesis of WA and $\mathrm{CA} M$. domestica was investigated in this study. The opossums (four $\mathrm{CA}$ and four WA) were placed in the metabolic chamber at a $T_{\mathrm{a}}$ of $28^{\circ} \mathrm{C}$ and heat production was estimated for $60 \mathrm{~min}$. They were then quickly removed from the chamber and injected intraperitoneally via a $27 \mathrm{G}$ hypodermic needle with noradrenaline $(3 \mu \mathrm{mol} / \mathrm{kg})$ and then replaced in the chamber. Heat production was subsequently monitored for a further $60 \mathrm{~min}$. Sham trials were also carried out in which sterile saline was injected instead of noradrenaline.

\section{Statistical analysis}

All comparisons made between acclimated groups were tested using Student's $t$-tests. Comparisons between different temperatures within groups were made using a Student Newman-Keuls test following analysis of variance (Sokal and Rohlf, 1969).

\section{RESULTS}

A summary of the results showing the variation with ambient temperature of the heat balance of $\boldsymbol{M}$. domestica is given in Table 1 . This table includes the responses of warm and cold acclimated animals for experiments in both air and helox. These data, together with a summary of the statistical analysis, are presented graphically in Figs 1 and 2.

The values obtained near $30^{\circ} \mathrm{C}$ for the WA $M$. domestica are those within the thermoneutral zone (the zone of vasomotor regulation)-note the elevated value for conductance. The responses of WA mammals appear to correspond with those obtained from laboratory-kept non-acclimated animals. Smith and Dawson (1985) noted this for the Australian marsupial $D$. byrnei. Therefore the BMR noted for the WA opossums can be compared with previously reported marsupial values. In mass independent units $M$. domestica has a BMR of $1.83 \mathrm{~W} / \mathrm{kg}^{0.75}$ as compared with $2.35 \mathrm{~W} / \mathrm{kg}^{0.75}$, the value given for Australian marsupials (Dawson and Hulbert, 1970). The value for $M$. domestica from this study is marginally lower than that reported for these marsupials by Thompson and Nicoll (1986). Body temperatures were also found to be low in these conditions, with 
Table 1. Influence of warm and cold acclimation on the heat balance of Monodelphis domestica at different temperatures in air and in helium-oxygen

\begin{tabular}{|c|c|c|c|c|c|c|}
\hline $\begin{array}{l}\text { Experimental } \\
\text { condition }\end{array}$ & $\begin{array}{c}T_{\mathrm{a}} \\
\left({ }^{\circ} \mathrm{C}\right)\end{array}$ & $\begin{array}{l}\text { Mass } \\
(\mathbf{k g})\end{array}$ & $\begin{array}{c}T_{b} \\
\left({ }^{\circ} \mathbf{C}\right)\end{array}$ & $\begin{array}{l}\text { Heat produced } \\
(W / \mathbf{k g})\end{array}$ & $\begin{array}{c}\text { Conductance } \\
\left(\mathrm{W} / \mathrm{m}^{2} \text { per }{ }^{\circ} \mathrm{C}\right)\end{array}$ & $N$ \\
\hline \multirow{6}{*}{$\begin{array}{l}\text { Warm acclimated } \\
\text { air }\end{array}$} & $29.9 \pm 0.3$ & $0.104 \pm 0.007$ & $32.6 \pm 0.4$ & $3.2 \pm 0.1$ & $6.4 \pm 0.5$ & 6 \\
\hline & $24.9 \pm 0.2$ & $0.102 \pm 0.007$ & $31.8 \pm 0.7$ & $5.6 \pm 0.3$ & $3.9 \pm 0.3$ & 5 \\
\hline & $19.9 \pm 0.3$ & $0.102 \pm 0.007$ & $31.9 \pm 0.6$ & $9.0 \pm 0.7$ & $3.4 \pm 0.2$ & 5 \\
\hline & $15.0 \pm 0.2$ & $0.108 \pm 0.008$ & $31.4 \pm 1.3$ & $11.8 \pm 0.3$ & $3.5 \pm 0.1$ & 5 \\
\hline & $9.8 \pm 0.2$ & $0.100 \pm 0.008$ & $33.8 \pm 0.8$ & $17.6 \pm 0.9$ & $3.5 \pm 0.2$ & 6 \\
\hline & $5.5 \pm 0.2$ & $0.102 \pm 0.008$ & $33.9 \pm 0.6$ & $21.1 \pm 1.7$ & $3.5 \pm 0.1$ & 5 \\
\hline \multirow{6}{*}{$\begin{array}{l}\text { Cold acclimated } \\
\text { air }\end{array}$} & $29.5 \pm 0.2$ & $0.093 \pm 0.007$ & $33.5 \pm 0.4$ & $6.6 \pm 0.3$ & $7.7 \pm 0.4$ & 6 \\
\hline & $25.3 \pm 0.2$ & $0.096 \pm 0.007$ & $32.4 \pm 0.5$ & $8.3 \pm 0.8$ & $5.2 \pm 0.2$ & 5 \\
\hline & $20.0 \pm 0.1$ & $0.091 \pm 0.008$ & $33.3 \pm 0.5$ & $13.7 \pm 0.7$ & $4.7 \pm 0.3$ & 5 \\
\hline & $14.9 \pm 0.2$ & $0.091 \pm 0.008$ & $34.1 \pm 0.6$ & $17.8 \pm 0.6$ & $4.2 \pm 0.2$ & 5 \\
\hline & $10.4 \pm 0.1$ & $0.094 \pm 0.009$ & $33.9 \pm 0.6$ & $18.7 \pm 1.3$ & $3.6 \pm 0.2$ & 5 \\
\hline & $5.0 \pm 0.2$ & $0.097 \pm 0.009$ & $33.0 \pm 0.5$ & $20.9 \pm 1.4$ & $3.4 \pm 0.2$ & 5 \\
\hline \multirow{2}{*}{$\begin{array}{l}\text { Warm acclimated } \\
\text { helox }\end{array}$} & $14.9 \pm 0.2$ & $0.101 \pm 0.008$ & $32.3 \pm 0.5$ & $27.8 \pm 0.7$ & $7.5 \pm 0.3$ & 5 \\
\hline & $10.0 \pm 0.1$ & $0.101 \pm 0.006$ & $29.6 \pm 1.0^{*}$ & $29.5 \pm 0.7^{*}$ & $6.9 \pm 0.2$ & 5 \\
\hline Cold acclimated & $14.8 \pm 0.2$ & $0.097 \pm 0.008$ & $32.2 \pm 0.4$ & $23.6 \pm 1.5$ & $6.3 \pm 0.3$ & 5 \\
\hline helox & $10.1 \pm 0.2$ & $0.097 \pm 0.007$ & $30.2 \pm 0.6$ & $28.4 \pm 1.4$ & $6.3 \pm 0.2$ & 5 \\
\hline
\end{tabular}

Values are \pm SE.

*Animals under these conditions were removed from the chambers prior to the completion of the normal equilibrium period.

the mean being $32.6 \pm 0.4^{\circ} \mathrm{C}$ against the average value of about $35.5^{\circ} \mathrm{C}$ reported for the marsupials in the study of Dawson and Hulbert (1970).

The responses of the WA animals to lower $T_{\mathrm{a}} \mathrm{s}$ followed the pattern expected for a competent homeotherm. Body temperature was maintained through an increase in HP and a reduced conduc- tance (Figs 1 and 2). At $5^{\circ} \mathrm{C}$ metabolism was maintained some 6.5 times above the BMR. To obtain the maximum sustained metabolic capability of these $M$. domestica helox was employed. At a temperature of $15^{\circ} \mathrm{C}$ in this environment the heat production was sustained at 8.7 times the BMR for more than $2 \mathrm{hr}$. At $10^{\circ} \mathrm{C}$ in helox, $\mathrm{HP}$ reached $29.5 \mathrm{~W} / \mathrm{kg}$ or 9.3 times

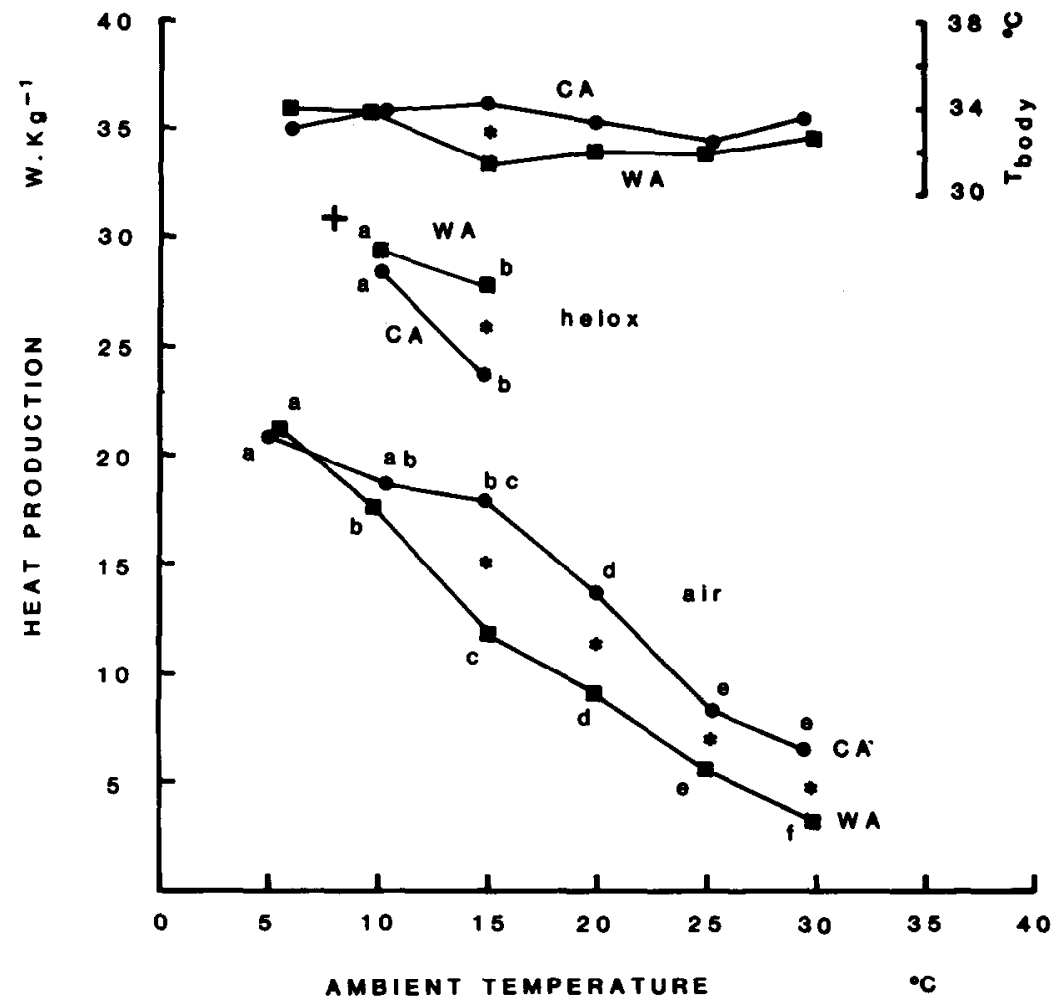

Fig. 1. Influence of acclimation on the thermogenic responses of the opossum $M$. domestica to varying environmental temperatures in air and helium-oxygen. CA indicates cold acclimated opossums and WA warm acclimated opossums. WA opossums in helox at $10^{\circ} \mathrm{C}$ (indicated by + ) did not maintain $\mathrm{HP}$ for the $2 \mathrm{hr}$ initial equilibration period. Statistically significant differences $(P<0.05)$ between acclimated groups at various $T_{\mathrm{a}} \mathrm{s}$ are shown as *. Significant differences within groups at different $T_{\mathrm{a}} \mathrm{s}$ are indicated by different letters. 


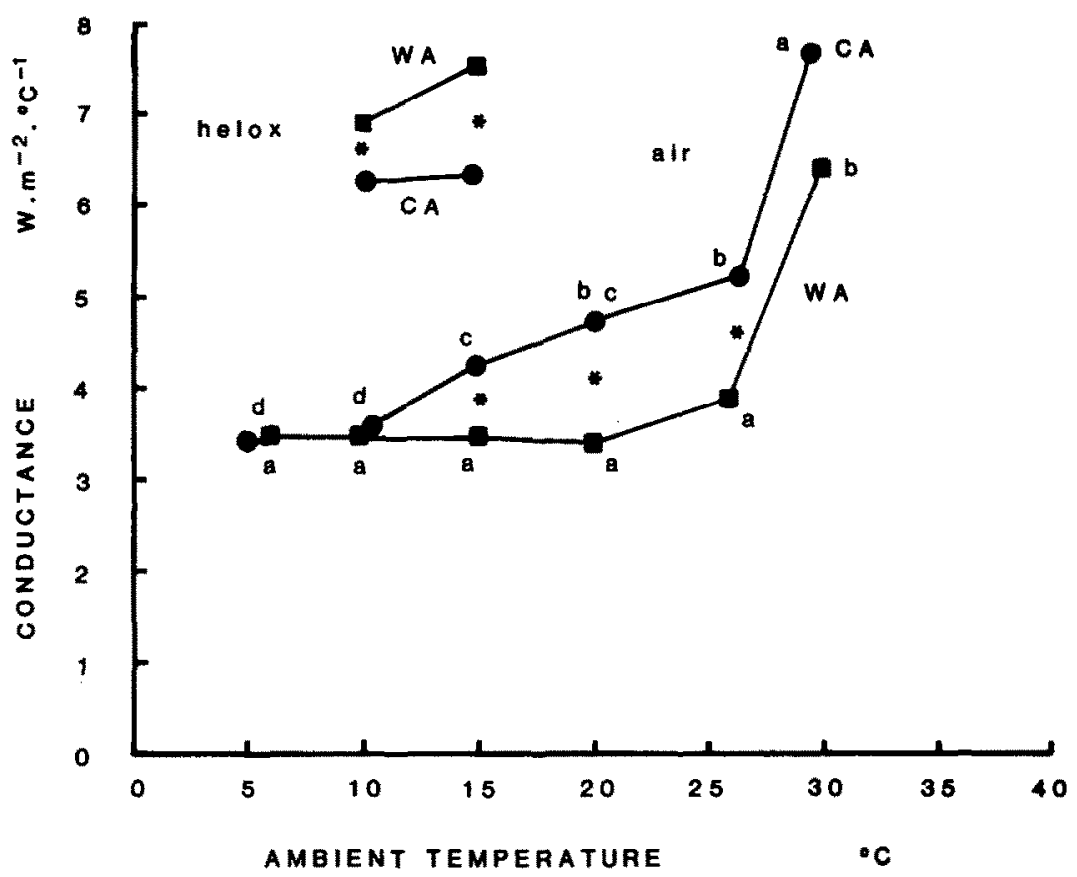

Fig. 2. Influence of acclimation on the heat loss characteristics, i.e. conductance, of the opossum $M$. domestica at varying environmental temperatures in air and helium-oxygen. Statistically significant differences $(P<0.05)$ between acclimated groups at various $T_{\mathrm{a}} \mathrm{s}$ are shown as *. Significant differences within groups at different $T_{\mathrm{a}} \mathrm{s}$ are indicated by different letters.

the basal rate but not all the animals could sustain these levels for the $2 \mathrm{hr}$ equilibration and $0.5 \mathrm{hr}$ measurement period, especially the smaller females. However, even these opossums could maintain the high rates for over $1 \mathrm{hr}$. The $T_{\mathrm{b}} \mathrm{s}$ reported for these conditions are those taken on the removal of the animal from the chamber. They represent values taken approx. 3-4 min after heat production showed its marked decline.

Cold acclimation produced marked changes in the heat balance of $M$. domestica, especially at the warmer air temperatures. At $30^{\circ} \mathrm{C}$ the $\mathrm{HP}$ was more than doubled (sce also Fig. 3). An clevated HP was seen at $T_{\mathrm{a}} \mathrm{s}$ down to $15^{\circ} \mathrm{C}$ but at $10^{\circ} \mathrm{C}$ (the acclimation temperature) and lower, there was no significant difference between the CA and WA animals (Fig. 1). In helox at $15^{\circ} \mathrm{C}$ the HP of the CA animals actually was lower than that of the WA animals. At $10^{\circ} \mathrm{C}$ there was no significant difference in the summit metabolism between the CA and WA animals but the CA animals were able to maintain the high HP for the full exposure. Examination of the experiments suggested that the summit metabolism reported for CA $M$. domestica may be close to the animal's limit, especially for the smaller females.

While this study concentrated on the ability of

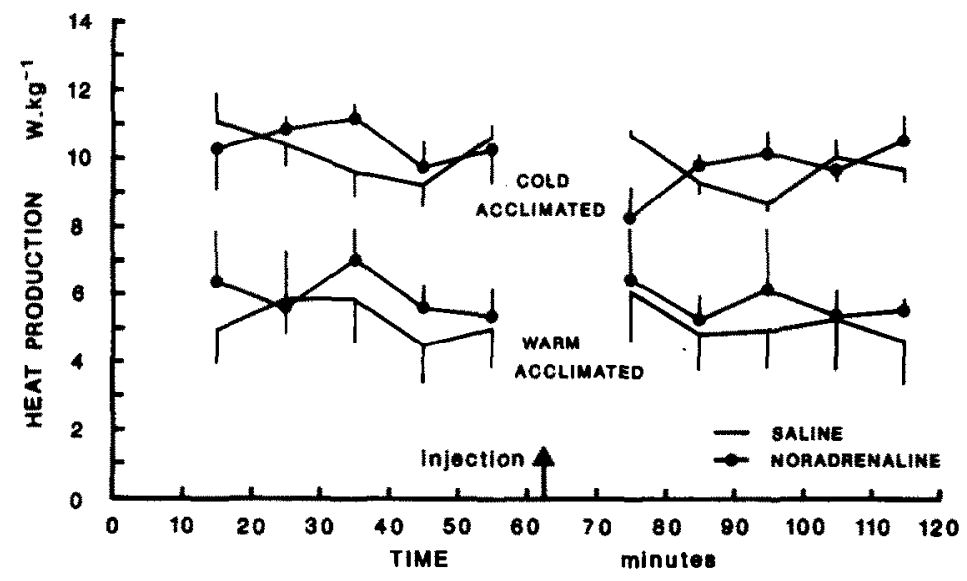

Fig. 3. Noradrenaline, $3 \mu \mathrm{mol} / \mathrm{kg}$, and sterile saline injections (intraperitoneal) lack a significant effect on the heat production of warm and cold acclimated $M$. domestica. Values are means of 10 -min periods, estimations having been made every minute. Values obtained for $10 \mathrm{~min}$ after the closure of the metabolic chamber were discarded. Vertical bars indicate the SE. 
$M$. domestica to sustain a level of HP, we did examine peak metabolic rates reached for a few minutes, in helox at $10^{\circ} \mathrm{C}$. Such rates were seen early in the exposure, often after about $20 \mathrm{~min}$, and were 11-13 times the BMR established for WA animals. The values were not different between groups, being $32.8 \pm 0.97$ and $32.7 \pm 2.52 \mathrm{~W} / \mathrm{kg}$ for $\mathrm{WA}$ and $\mathrm{CA}$ animals respectively.

Since the $T_{\mathrm{b}} \mathrm{s}$ of the two groups were not markedly different the differences in HP were paralleled by changes in heat loss, i.e. conductance (Fig. 2). The variation of the conductances in the WA animals with changing air temperature followed the "Newtonian" pattern usually reported for small mammals (Hinds and MacMillen, 1984) but that in the CA group did not. These remained elevated until a $T_{\mathrm{a}}$ of $10^{\circ} \mathrm{C}$, the acclimation temperature, was reached. In the extreme environment, helox, the conductances of the $\mathrm{CA}$ $M$. domestica were significantly lower than those of the WA animals.

In placentals non-shivering thermogenesis is mediated by noradrenaline (NA). During the course of our study intraperitoneal injections were made of noradrenaline, at levels $(3 \mu \mathrm{mol} / \mathrm{kg})$ that would be $\mathrm{cx}$ pected to give a positive response in a small placental (Reynolds and Hulbert, 1982; Heldmaier and Buchberger, 1985) and a level that has becn reported to give a response in an immature marsupial (Loudon et $a l ., 1985)$. These injections were made into both WA and CA $M$. domestica, which were resting at a $T_{\mathrm{a}}$ of $28^{\circ} \mathrm{C}$. The subsequent pattern of heat production was not different in either group from that seen following equivalent injections of sterile saline (Fig. 3). The experimental protocol used in these experiments produces a marked thermogenic response in cold acclimated laboratory rats (Smith, 1984).

\section{DISCUSSION}

Monodelphis domestica, a South American didelphid marsupial, appears to have a high aerobic metabolic capacity. This is despite its low basal or standard metabolic rate. The summit metabolism, when cold acclimated, would enable these small opossums to cope with air temperatures well below zero for considerable periods. Similar capacities have been noted in some Australian species (Dawson and Dawson, 1982; Smith and Dawson, 1985). Consequently, it is possible that marsupials in general have large metabolic capabilities, as was initially suggested by Dawson and Needham (1981) from their studies into the allometry of the cardiovascular and respiratory systems of this group.

Small placentals can achieve metabolic levels 6-7 times their BMR but these can only be maintained for short periods (5-10 min) and therefore are best described as peak metabolic rates (Hart, 1957; Rosenmann and Morrison, 1974; Chappell, 1984). Such placentals only seem capable of a summit metabolism in response to cold which is $3-5$ times BMR (Gelineo, 1964; Dawson and Dawson, 1982). $M$. domestica had a BMR that was low even by the standards of other marsupials, $78 \%$ of the mean value reported for Australian marsupials (Dawson and Hulbert, 1970) and only $55 \%$ of the value predicted for placentals from the equation of Kleiber
(1961). Despite this, it had a summit metabolism that was 9 times its BMR and 5 times that of the predicted BMR for a placental of similar mass. The heat loss characteristics of most small mammals are necessarily similar because of physical constraints (Dawson and Dawson, 1982; Hinds and MacMillen, 1984) so that when a small marsupial maintains $T_{\mathrm{b}}$ at a low $T_{\mathrm{a}}$ it has comparable levels of thermogenesis to placentals. Whether the absolute aerobic capacities of many marsupials exceed those of placentals has yet to be resolved, but it is a possibility.

The high aerobic scope in marsupials answers some general questions concerning thermoregulation in small mammals. McNab (1983), in his discussion on the limits to endothermy, developed the idea that the ability to maintain continuous endothermy was determined by the interaction of body mass and BMR. From plots of these functions he put forward the concept of a minimum boundary curve for endothermy. McNab found the energetics of small marsupials difficult to explain because they transgressed his minimum boundary curve and in his recent discussion of marsupial energetics (McNab, 1986) they are described as an enigma. This enigma is now resolved because the endothermic abilities of marsupials are not constrained by their BMR in the same way as those of placentals.

Placentals can increase their thermogenic capabilities in some conditions via an increase in nonshivering thermogenesis. In the laboratory this may be seen in cold acclimation (Depocas et al., 1957; Hart, 1960; Kiang-Urich and Horvath, 1979). The increase in maximum heat production (usually of the order of $30 \%$ ) is associated with the potentiation of regulatory non-shivering thermogenesis. This form of heat production is mediated by noradrenaline and occurs mainly in brown adipose tissue.

That marsupials, as a group, may differ from placcntals in their responses to acclimation is suggested by the results of $M$. domestica and those of the Australian marsupial, Dasyuroides byrnet (Smith and Dawson, 1984, 1985). A principal difference between the marsupials and placentals in their responses to acclimation is that there is no marked increase in the summit (or peak) metabolism of marsupials, although there is an increase in the time that they can maintain the summit.

Noradrenaline mediated NST appears of little importance or is absent in adult marsupials (Nicol, 1978; Wallis, 1979; Reynolds and Hulbert, 1982). The data from the current study indicating a lack of effect of NA on the metabolism of $M$. domestica (Fig. 3) supports these conclusions. Such a result would not be unexpected since BAT has not been found in marsupials (Rowlatt et al., 1971), even by electronmicroscopic investigation (Fleming, 1982). However, recent work by Loudon et al. (1985) reports NAmediated heat production and BAT in the immature pouch-young of a wallaby. The significance of regulatory NST in marsupials therefore appears equivocal and needs resolution.

If the status of NST in marsupials is equivocal, what is the nature of the elevated HP seen at moderate and higher air temperatures in CA $M$. domestica (Figs 1 and 3 ) and also reported in D. byrnei (Smith and Dawson, 1985)? It does not seem to be some 
form of regulatory NST because it is not maintained at colder temperatures, which is markedly at variance with acclimation responses seen in some placentals.

Perhaps long-term cold exposure results in an overall change in the basal level of metabolic activity commensurate with the heat production required to maintain $T_{\mathrm{b}}$ at the acclimation $T_{\mathrm{a}}$. In these experiments this was approx. $10^{\circ} \mathrm{C}$ and it is notable that at $10^{\circ} \mathrm{C}$ the HP and the conductance of the $\mathrm{CA}$ animals were not significantly different from those of the WA group. The nature of the mechanisms that lead to such a pattern of responses is difficult to explain but probably involves a general increase in metabolic activity and substrate mobilization. In $D$. byrnei cold acclimation results in a marked increase in liver size (Smith, 1984). Hart (1971) stresses that the elevation in basal metabolism seen in some rodents is not an important feature of acclimation to constant cold, but a symptom of it. What is important is the increased ability to maintain homeothermy in cold environments and the nature of this response differs between placentals and marsupials.

Although Australian and American marsupials have had a long evolutionary separation it seems that both groups have a high metabolic capacity despite their low BMR. Does this have implications for our thinking about other marsupial characteristics? In this respect, recent data concerning the energetics of marsupial reproduction are interesting. Thompson and Nicoll (1986) report that $M$. domestica sustains a high maternal metabolism during lactation. This finding tends to conflict with the suggestion of $\mathrm{McNab}$ (1986) that the marsupials cannot tolerate cold temperate environments because they cannot provide the energy to accelerate growth and development of the young to complete reproduction within a short spring and summer. When considering such matters it should be remembered that marsupials have had a long cvolutionary history in the far southern regions of the earth, at times when this part of the world would have had at least cold temperate climate (Archer, 1984).

Acknowledgements - The considerable assistance and advice of Dr W. R. Dawson is acknowledged, with the study being supported by a grant NSF BSR 84-07592 to Dr W. R. Dawson and Study Leave Support to Dr T. J. Dawson from the University of New South Wales, Australia. Advice on the acquisition and maintenance of the $M$. domestica was given by $\mathbf{P}$. Pridmore.

\section{REFERENCES}

Archer M. (1984) The Australian marsupial radiation. In Vertebrate Zoogeography and Evolution in Australia (Edited by Archer M. and Clayton G.), pp. 633-808. Hesperian Press, Perth.

Bartholomew G. A., Vleck D. and Vleck C. M. (1981) Instantaneous measurement of oxygen consumption during pre-flight warm-up and post-flight cooling in sphingid and saturniid moths. $J$. exp. Biol. 90, 17-32.

Brice A. G. and Welsh H. G. (1983) Metabolic and cardiorespiratory responses to $\mathrm{He}-\mathrm{O}_{2}$ breathing in exercise. J. appl. Physiol. Respirat. Environ. Exercise Physiol. 54, 387-392.

Cannon B. and Nedergaard J. (1983) Biochemical aspects of acclimation to cold. $J$. therm. Biol. 8, 85-90.

Chappell M. A. (1984) Maximum oxygen consumption during exercise and cold exposure in deer mice, Peromyscus maniculatus. Respiration Physiol. 55, 367-377.

Dawson T. J. (1973) Primitive mammals. In Comparative Physiology of Thermoregulation, Vol. III (Edited by Whilow G. C.), pp. 1-46. Academic Press, New York.

Dawson T. J. (1983) Monotremes and Marsupials: the Other Mammals. The Institute of Biology Studies in Biology, No. 150. Edward Arnold, London.

Dawson T. J. and Dawson W. R. (1982) Metabolic scope and conductance in response to cold of some dasyurid marsupials and Australian rodents. Comp. Biochem. Physiol. 71A, 59-64.

Dawson T. J. and Hulbert A. J. (1969) Standard energy metabolism of marsupials. Nature, Lond. 221, 383.

Dawson T. J. and Hulbert A. J. (1970) Standard metabolism, body temperature and surface areas of Australian Marsupials. Am. J. Physiol. 218, 1233-1238.

Dawson T. J. and Needham A. D. (1981) Cardiovascular characteristics of two resting marsupials: An insight into the cardio-respiratory allometry of marsupials. J. comp. Physiol. B. 145, 95-100.

Dawson T. J., Robertshaw D. and Taylor C. R. (1974) Sweating in the kangaroo: a cooling mechanism during exercise, but not in the heat. Am. J. Physiol. 227, 494-498.

Depocas F., Hart S. J. and Heroux O. (1957) Energy metabolism of the white rat after acclimation in warm and cold environments. J. appl. Physiol. 10, 393-397.

Fadem B. H., Trupin G. L., Maliniak E., Vandeberg J. L. and Hayssen V. (1982) Care and breeding of the Gray, short-tailed opossum (Monodelphis domestica). Lab. Animal Sci. 94, 405-409.

Fleming M. R. (1982) The Thermal Strategies of Three Small Possums from South-eastern Australia. Ph.D. Thesis. Monash University, Clayton, Victoria, Australia.

Gelineo S. (1964) Organ systems in adaptation: the temperature regulating system. In Handbook of Physiology, Section 4 (Edited by Dill D. B.), pp. 259-282. American Physiology Society, Washington DC.

Hart J. S. (1957) Climatic and temperature induced changes in the energetics of homeotherms. Rev. Can. Biol. 16, 133-174.

Hart J. S. (1960) Energy metabolism during exposure to cold. Fedn Proc Fedn Am. Socs exp. Binl (.Suppl.) 19, 15-19.

Hart J. S. (1971) Rodents. In The Comparative Physiology of Thermoregulation, Vol. II (Edited by Whittow G. C.), pp. 1-149. Academic Press, New York.

Heldmaier G. and Buchberger A. (1985) Sources of heat during nonshivering thermogenesis in Djungarian hamsters: a dominant role of brown adipose tissue during cold adaptation. J. comp. Physiol. B. 156, 237-245.

Hinds D. S. and MacMillen R. E. (1984) Energy scaling in marsupials and eutherians. Science 225, 335-337.

Jansky L. (1973) Non-shivering thermogenesis and its thermoregulatory significance. Biol. Rev. 48, 85-132.

Kiang-Urich M. and Horvath S. M. (1979) Effects of cold acclimation and 6-OHDA sympathectomy on the cold tolerance of rats. J. therm. Biol. 4, 233-237.

Kleiber M. (1961) The Fire of Life. John Wiley, New York.

Loudon A., Rothwell, N. and Stock, M. (1985) Brown fat, thermogenesis and physiological birth in a marsupial. Comp. Biochem. Physiol. 81A, 815 819.

MacMillen R. E. and Nelson J. E. (1969) Bioenergetics and body size in dasyurid marsupials. Am. J. Physiol. 217, 1246-1251.

McNab B. K. (1978) The comparative energetics of neotropical marsupials. J. comp. Physiol. 125, 115-128.

McNab B. K. (1983) Energetics, body size, and the limits to endothermy. J. Zool., Lond. 199, 1-29.

McNab B. K. (1986) Food habits, energetics and reproduction of marsupials. J. Zool., Lond. A208, 595-614.

Nicholls D. G. and Locke R. (1984) Thermogenic mechanisms in brown fat. Physiol. Rev. 64, 1064. 
Nicol S. C. (1978) Non-shivering thermogenesis in the potoroo, Potorous tridactylus (Kerr). Comp. Biochem. Physiol. 59C, 33-37.

Porter W. P. (1969) Thermal radiation in metabolic chambers. Science 166, 115-117.

Reynolds W. and Hulbert A. J. (1982) Cold acclimation in a small dasyurid marsupial: Antechinus stuartii. In Carnivorous Marsupials, Vol. I (Edited by Archer M.), pp. 279-283. Royal Zoological Society of New South Wales, Australia.

Rosenmann M. and Morrison P. (1974) Maximum oxygen consumption and heat loss facilitation in small homeotherms by $\mathrm{He}-\mathrm{O}_{2} . A m$. J. Physiol. 226, 490-495.

Rothwell N. J. and Stock M. J. (1985) Biological distribution and significance of brown adipose tissue. Comp. Biochem. Physiol. 82A, 745-751.

Rowlatt V., Mrosovsky N. and English A. (1971) A comparative survey of brown fat in the neck and axilla of mammals at birth. Biologia Neonate 17, 53-84.
Smith B. K. (1984) The Metabolic Basis of Cold Acclimation in Small Marsupials. Ph.D. Thesis. University of New South Wales, Kensington, N.S.W.

Smith B. K. and Dawson T. J. (1984) Changes in the thermal balance of a marsupial (Dasyuroides byrnei) during cold and warm acclimation. J. therm. Biol. 9, 199-204.

Smith B. K. and Dawson T. J. (1985) Use of helium-oxygen to examine the effect of cold acclimation on the summit metabolism of a marsupial, Dasyuroides byrnei. Comp. Biochem. Physiol. 81A, 445-449.

Sokal R. R. and Rohlf F. J. (1969) Biometry. Freeman, San Francisco, California.

Thompson S. D. and Nicoll, M. E. (1986) Basal metabolic rate and energetics of reproduction in entherian mammals. Nature 321, 690-693.

Wallis R. L. (1979) Responses to low temperatures in small marsupial mammals. J. therm. Biol. 4, 105-111. 